\title{
EL ODIO. UNA RECONSIDERACIÓN
}

\author{
Hatred. A reconsideration
}

Ángel Garrido Maturano*

\section{Resumen}

El artículo, a partir de una crítica a la concepción axiológica de Scheler, realiza un análisis fenomenológico-hermenéutico del odio que se concentra en la índole ontológica del fenómeno. Desde el punto de vista fenomenológico describe los rasgos estructurales esenciales que posibilitan el surgimiento del odio. Dicha descripción se despliega tanto desde la perspectiva del modo en que se experimenta a sí mismo el sujeto que odia, cuanto del modo en que se da el objeto odiado. Desde el punto de vista hermenéutico explicita el significado positivo y negativo del odio tanto en el plano ontológico como en el ético.

$$
<\text { Odio }><\text { Intencionalidad }><\text { Ontología }><\text { Ética }>
$$

\begin{abstract}
On the basis of a criticism of Scheler's axiological theory, this article advances a phenomenological and hermeneutic analysis of hatred. The analysis focuses on the ontological character of the phenomenon. From a phenomenological point of view, it describes the essential structural traits that render possible the emergence of hatred. This description is developed considering both the modes in which the subject that hates experiences itself and the modes in which the hated object is given. From a hermeneutic point of view, the article explains the positive and negative meaning of hatred, both in the ontological and in the ethical level.
\end{abstract}

$$
<\text { Hatred }><\text { Intentionality }><\text { ontology }><\text { Ethics }>
$$

\footnotetext{
* Dr. en Filosofía. Conicet-UNNE. hieloypuna@hotmail.com
} 


\section{Introducción}

Si en el orbe de los sentimientos hay un fenómeno que siempre gozó de mala fama y peor prensa es el del odio. A diferencia del amor, hijo dilecto de la afectividad, que supo disfrutar no sólo de los más sublimes versos del poeta, sino también de las más elevadas meditaciones del pensador, este otro hijo suyo, un poco deforme y ciertamente vergonzante, ha merecido muy poco el interés de la filosofía; y cuando ella se ha fijado en él lo ha hecho las más de las veces sólo para considerarlo desde la perspectiva de su afortunado hermano. Por momentos pareciera que a la filosofía no le importó verdaderamente el odio en su especificidad, sino que, si le ha dirigido la mirada, sólo ha visto en él el mero reverso del amor. Si se ha interesado por el odio, ha sido (casi siempre) únicamente para resaltar por contraste las ya luminosas virtudes de Eros. ${ }^{1}$

${ }_{1}$ Hasta donde mi conocimiento alcanza no son muchos los estudios específicamente dedicados al odio. Ante todo hay que destacar el ya antiguo, pero a mi modo de ver aún no superado trabajo de Aurel Kolnai, aparecido por primera vez con el título "Versuch uber den Haß", en: Philosophisches Jahrbuch der Görres-Gesellschaft, 44 Band, 2. Heft, 1931, pp. 317-331. Aquí citaremos la obra de Kolnai de acuerdo con la siguiente edición: Aurel Kolnai, Eckel, Hochmut, Haß. Zur Phänomenologie feindlicher Gefühle, Frankfurt a. M., Suhrkamp, 2007. También se ha ocupado del odio sin reducirlo a mero opuesto del amor Sartre en su tratado El ser y la nada (Sartre, 1966: 507-511). Sin embargo el autor sólo considera el odio en la perspectiva de la relaciones de objetivación mutua que caracterizan en El ser y la nada la vida intersubjetiva. Sartre no se interesa tanto por determinar cuáles son los rasgos esenciales y concretos que permiten reconocer una cierta intención afectiva como odio, sino que se centra en el carácter formal propio de la experiencia del sujeto que odia. Desde esta perspectiva Sartre analiza el odio como una "posición absoluta de la libertad del para-sí frente al otro" (Sartre, 1966: 509), es decir, como aquel modo de relación con el otro por el cual "el que odia proyecta no ser ya objeto en modo alguno" (Sartre, 1966: 509). Ciertamente Sartre tiene razón al considerar al odio reflexivamente y no sólo desde la perspectiva del correlato objetivo del fenómeno, esto es, al considerar no sólo el modo en que el odio comprende o abre lo odiado, sino también el modo en que el sujeto que odia se siente a sí mismo cuando lo hace. Sin embargo, a mi modo de ver, no llega a alcanzar lo específico del sentimiento, en cuanto quien odia no sólo odia la imagen objetiva que el otro hace de él ni el hecho de que pueda objetivarlo de uno u otro modo, sino que odia específicamente al otro. Alguien puede objetivarme del peor modo, pero si yo no tengo una relación personal con él, si no lo conozco personalmente ni he entrado en conflicto con él, puedo despreciar o desvalorizar esa imagen, pero propiamente no arde en mi interior ningún odio hacia esa persona que me objetiva. La consecuencia que lógicamente extrae Sartre de su posición fundamental, a saber, que el objeto de odio es la posibilidad de ser objetivado por el otro, no puede ser otra que la siguiente: el odio no es odio a un otro determinado, sino al prójimo como representante de la humanidad, es decir, "que el odio es odio de todos los otros en uno sólo" (Sartre, 1966: 510). Desde el punto de vista fenomenológico esta aseveración pareciera contradecir una característica esencial del odio, a saber, su especificidad. No odio a todo otro en uno, sino que el odio se dirige específicamente al ser así de alguien en tanto y en cuanto ese así expresa todo aquello con lo que estoy en conflicto. Podría decirse que no es el caso que odie a todos en la persona de uno, sino que, antes bien, la persona de uno expresa todo aquello que odio. Estas insuficiencias en el análisis sartreano surgen, a mi modo de ver, del hecho, que comparte con aquellos que supeditan su análisis del odio al amor, de no indagar el fenómeno por sí mismo, sino sólo en tanto y en cuanto le sirve para ejemplificar su estudio de los modos de objetivación que se cumplen en las relaciones entre el para-sí y el prójimo. Entre los trabajos que se han ocupado del fenómeno del odio en estricta correlación con el amor destacan, por cierto, los de Scheler y Ortega. La entera sección B de Esencia y formas de la simpatía (Scheler, 2004: 193-270) se titula "El amor y el odio" pero de hecho las referencias al último son mínimas comparadas con los extensos análisis del amor y, como he dicho, siempre para oponerlo o considerarlo como mera contra-cara del primero. Cosa parecida ocurre en los Estudios sobre el amor de José Ortega y Gasset (Ortega y Gasset, 1984: 64-74) 
Aquí, en contra de esta perspectiva, nos interesaremos por el odio en su especificidad y sólo lo compararemos con el amor en tanto la comparación pueda ayudar a elucidar la índole de un sentimiento tan legítimamente humano como lo es aquel y del que, tal vez, no deberíamos avergonzarnos del todo.

Un análisis que pretende describir el odio en su especificidad puede comprenderse, desde el punto de vista metodológico, en primer lugar, fenomenológico y en segundo, hermenéutico. El análisis es fenomenológico en cuanto no le interesa hacer una valoración moralizante acerca del odio; menos aún explicar los condicionamientos psicológicos y las experiencias traumáticas que hacen surgir en una cierta persona un determinado y concreto sentimiento de odio hacia alguna otra. Tampoco se propone realizar una tipología de las diferentes formas del odio. Su perspectiva no es ni moralista ni psicológica. De lo que aquí se trata es de describir aquellos rasgos estructurales que hacen posibles que el fenómeno se dé y que son esenciales a toda manifestación concreta del mismo. El método es, además, fenomenológico en cuanto parte del presupuesto, propio de la fenomenología, de que el odio no es un mero estado anímico, psicológico y subjetivo, sino que es un acto intencional por el cual un sujeto se refiere afectivamente a un correlato objetivo; y de aquel otro presupuesto que considera que esta referencia intencional debe ser considerada en su especificidad, es decir, no como un mero modo deficiente, por ejemplo respecto de la razón o de sentimientos "positivos" como el amor, de referirse a un objeto, sino como un modo genuino de abrirse a y relacionarse con una cierta forma de darse de ese mismo objeto. Pero, además, el método se comprende a sí mismo como hermenéutico. Por cierto que no se trata aquí de hermenéutica en el sentido de una cierta teoría de la interpretación de textos que se han ocupado, en este caso, del odio, sino que de lo que se trata es de una hermenéutica de la facticidad. Tal expresión no mienta otra cosa que el hecho de que lo que se da en aquella correlación intencional que configura el odio requiere, por su mismo modo de darse, explicitación, para que, por obra de esa explicitación, esto es, de la interpretación de algo como algo, pueda hacerse patente la plenitud de significación -en este caso ética y ontológicade lo que se da. El análisis y la explicitación persiguen dos objetivos. En lo que al primero respecta prima el momento descriptivo, en lo que al segundo el interpretativo. El primero radica, precisamente, en describir los fundamentos del odio y su estructura esencial, es decir, el análisis aspira a describir aquellas condiciones estructurales que permiten el surgimiento del odio y a determinar los rasgos esenciales del modo en que el sujeto intenciona al objeto en el fenómeno y, correlativamente, también del modo en que el objeto se le manifiesta al sujeto en la correlación. El segundo objetivo pretende reconsiderar el carácter absoluto de la mala fama que sufre el odio. Sobre la base de lo ganado en la descripción de sus características esenciales, pretendo, pues, poner a la luz aquella significación implícita o dimensión del odio que ha quedado oculta en la mayoría de los estudios a él dedicados. Pretendo mostrar en qué medida y de qué

quien realiza observaciones ciertamente luminosas acerca del fenómeno, pero que distan mucho de ser un análisis suficiente del mismo y que en todos los casos se reducen a mostrar su oposición y su paralelismo al amor. A favor de Ortega puede decirse, empero, que su estudio es sobre el amor y no, como el de Scheler, sobre "El amor y el odio". 
manera el odio puede significar positivamente tanto en el plano ontológico cuanto en el ético.

Dado que ha sido Max Scheler quien fundamentalmente extrajo el estudio del odio (y de los otros sentimientos) tanto de la perspectiva psicologista, para la cual el fenómeno no era sino un estado de ánimo subjetivo que no se refería intencionalmente a objeto alguno, cuanto de la racionalista, para la cual el odio, aunque se refería a un objeto, sólo lo veía deformado a través de los ojos nublados por la pasión, me parece que todo análisis fenomenológico del odio debe comenzar considerando el aporte de Scheler y, sobre todo, los problemas que su concepción deja abiertos.

\section{Análisis de la comprensión scheleriana del odio}

Scheler se ha percatado de que el odio, como el amor, no es ciego; no ve "peor" lo mismo que el ojo de la razón vería "mejor", sino que ve otras cosas. Ahora bien, inmediatamente Scheler identifica esas otras cosas con valores. El odio, como el amor, "hace que se vean valores más altos o más bajos que los que se pueden ver con el ‘ojo’ de la razón” (Scheler, 2004: 196). El odio no sería, entonces, un acto meramente negativo que por su propia naturaleza deformaría el ser del objeto al que se refiere, sino un acto positivo de una índole muy peculiar. ¿Cuál? Pues bien, lo específico del odio consiste en que el capta un "disvalor" o valor negativo, tanto como el amor lo hace con un valor positivo. "Pero mientras que el amor es un movimiento que va del valor más bajo al más alto y en el que relampaguea por primera vez en cada caso el valor más alto de un objeto o de una persona, el odio es un movimiento opuesto" (Scheler, 2004: 200). Es decir, desde la captación de un disvalor portado por su objeto se dirige hacia la posible existencia de los valores más bajos de ese mismo objeto y, concomitantemente, anula la posible existencia del valor más alto. En otros términos, el odio proyectaría una suerte de imagen "anti-ideal" de los disvalores portados por el objeto odiado. Pero no la proyecta caprichosamente, sino que lo hace en tanto y en cuanto en los disvalores, ya dados en lo odiado y que el odio puede "ver" con una agudeza que les es extraña a otras facultades, ese "anti-ideal" se halla latente como aquello a lo que posiblemente conduzca la dinámica del propio ser del objeto odiado. De allí que el odio, aunque tienda a la anulación ${ }^{2}$ de los valores positivos, de su objeto no sea un cerrarse en general al todo del reino de los valores, sino un "positivo dirigir la vista al posible valor más bajo" (Scheler, 2004: 200). Así concebido, el odio es un movimiento intencional que, partiendo del disvalor A dado en un objeto y por él captado, permite que aparezca la posibilidad de un disvalor aún peor $\mathrm{B}$, al que la dinámica del ser del objeto tiende. El odio no odiaría, entonces, ni el ser empírico existencial de su objeto ni algo que éste quiera o crea que debe ser, sino aquello que éste está "en trance de" o llegando a ser y

\footnotetext{
2 No hay que malentender el sentido con el que M. Scheler (2004: 200-202) utiliza el término "anulación" o "aniquilación" del valor positivo por parte del odio. No se trata, para Scheler, de que el odio elimine de hecho las cualidades positivas del objeto odiado - por eso podemos odiar a alguien a pesar de sus innegables virtudes, como podemos amarlo a pesar de sus innúmeros defectos- sino que se cierra a la captación de estos valores.
} 
que se anuncia como la consumación de su realidad más propia. La consecuencia de ello es que, como adelantábamos, el odio a una cierta persona empíricamente dada esboza siempre una "imagen anti-ideal de disvalores" la cual -insiste Scheler (2004: 201) - no es ni una construcción arbitraria ni una mera proyección afectiva, sino que puede ser tomada al mismo tiempo como la verdadera realidad axiológica del objeto odiado, sólo que todavía no dada en el sentir, pero sí anunciada en los disvalores ya dados en tal sentir. En cuanto el objeto del odio no es, propiamente hablando, la persona odiada, sino esta imagen, el odio no tiene necesariamente un correlato intencional específicamente humano. Podemos odiar a todo objeto capaz de una potenciación del disvalor, así como podemos amar todo aquello que es capaz de una elevación del valor. Sin embargo, el autor no puede ofrecer ni un sólo ejemplo de un odio que no fuera dirigido hacia un ser humano o a un objeto en cuanto refleja sentimentalmente rasgos originariamente propios de un ser humano. Finalmente digamos que en cuanto el odio, como el amor, son aquellos actos afectivos intencionales que agudizan nuestra mirada para poder ver los valores estrictamente individuales de una persona u objeto, sólo gracias a ellos brota la persona individual pura e íntegramente. Si el amor o el odio desaparecen, "surge al punto en lugar del 'individuo', la 'persona social', esa mera x de diversas relaciones, la $\mathrm{x}$ de una determinada actividad social" (Scheler, 2004: 201).

Hasta aquí hemos recordado los rasgos fundamentales de la suficientemente conocida comprensión scheleriana del odio. A mi modo de ver ella implica tres aportes fundamentales. En primer lugar, el advertir que el odio en tanto sentimiento es un acto intencional referido a un objeto específico y no un mero estado subjetivo, una turbia pasión que encierra al sujeto en sí mismo. En segundo lugar, el hecho de que el odio (como el amor) puede referirse de modo apropiado a su objeto, es decir, que el odio no ve peor lo que la razón vería mejor, sino que, a diferencia de esta última, es concernido, interesado, movido por aspectos del objeto - para Scheler disvalores- que no pueden ser considerados neutralmente, sino que implican, por su propio modo de darse, una toma posición del sujeto respecto de ese objeto. Así, por ejemplo, quien odia la maldad de una persona o su carácter resentido y violento no puede llegar a comprender la plenitud de significatividad propia de lo que odia a través de una posición teórica neutral, pues lo odiado significa en esencia de modo práctico y sólo se puede acceder al modo en que se me da o aparece el objeto odiado desde el sentirse afectado o concernido prácticamente por esas características bajo la forma del odio. El tercer aporte, consecuencia directa de los dos anteriores, no es otro que el siguiente: el odio como acto presenta un carácter positivo. No es el mero reverso negativo del amor. No nos cierra el acceso al objeto o al mundo, sino que descubre un aspecto del objeto o del mundo -para Scheler, su imagen axiológica anti-ideal- al que no tenemos acceso sino a través de él. Sin embargo, el análisis de Scheler deja también tres problemas abiertos que deben ser reconsiderados por todo análisis fenomenológico del odio.

El primero de esos problemas tiene que ver con la determinación del objeto odiado que, para Scheler, es una imagen anti-ideal de disvalores, es decir, lo odiado no es la persona o el objeto, su ser así en el mundo y el modo en que ese así me concierne a 
mí en mi propio ser, sino una imagen de valores, de la cual lo odiado sólo es portador y a la que yo odiaría por una mera reacción intuitiva provocada por la cualidad axiológica de esa imagen. ${ }^{3}$ Esta determinación trae a colación inevitablemente el problema del estatus ontológico del valor o, dicho de otro modo, el nexo entre ser y valor. Los valores serían puras esencialidades subsistentes que sólo ocasionalmente resultarían portadas por los bienes. El espíritu humano se elevaría, entonces, más allá de la experiencia del ser del ente que lo porta hasta un puro sentir la imagen ideal de valores o disvalores que en él se encarna. Como señala S. Strasser, desde el punto de vista fenomenológico, esta tesis resulta insostenible. Strasser ofrece un ejemplo sumamente significativo. Supongamos que en una ciudad de aguda crisis habitacional a un potencial inquilino se le ofrece una casa cómoda, amplia, de bello diseño, etc. etc., a la que sólo le falta un detalle: el ser, la existencia. Es obvio que todos los presuntos valores de la casa "se precipitan en la nada de la absoluta falta de valor tan pronto como a ella le es privado el valor fundamental, el valor de ser" (Strasser, 1956: 18). La conclusión es clara. Al valor o disvalor de los bienes "les pertenece en general y necesariamente su ser o su poder ser como fundamento ontológico; en otras palabras: el valor está unido al ser de una manera indisoluble" (Strasser, 1956:18). Y si el ser es el fundamento de toda propiedad axiológica, entonces el objeto del odio no puede ser una pura imagen axiológica, sino el ser así de un determinado individuo. No odiamos la maldad en alguien, sino la maldad de alguien, es decir, el modo en que es conmigo en el mundo un determinado individuo, y no el modo en que idealmente pueden llegar a encarnarse en él oscuras entidades llamadas valores. No resulta para nada evidente cuál sería el estatus epistémico de estas formas puras que, paradójicamente, no significarían nada privadas de su relación ontológica con su objeto. En efecto, nadie odia la maldad en sí. La maldad en sí es una abstracción y, como tal, objeto del intelecto y no del sentir. Podemos comprender o conceptualizar la maldad o la envidia, pero no odiarlas. Odiamos el ser malo, envidioso o, incluso, las bondades de alguien. De hecho la teoría de Scheler no puede dar cuenta del hecho fenoménico indubitable de que, por resentimiento o envidia, odiamos incluso los valores en cuanto son de alguien, pues lo que odiamos no son los valores, sino el ser así de ese alguien. Incluso es usual que el odio por alguien crezca cuanto más se le reconocen sus valores, y más se desprecie y se quiera aniquilar al objeto odiado cuanto más brillantes sean los valores que él realiza. De allí que el primer problema que nos deja abierto Scheler sea el de la determinación del objeto del odio. Si no es el valor ni una imagen de valores, sino el ser así de un individuo particular que se abre positivamente en el odio para el sujeto que odia, entonces ¿cómo habrá que entender ese así? ¿Cuál es el fundamento del odio?

\footnotetext{
3 Ciertamente Scheler reconoce que el amor y el odio nos revelan la imagen de valores que es estrictamente peculiar al individuo que los porta. Por ello son estos sentimientos los que nos revelan el sujeto en su estricta particularidad. Sin embargo, no se ve muy bien cómo los valores pueden ser autónomos respecto del ser que los porta y valer objetivamente, siendo que, a la vez, son estrictamente propios de un ser individual. A mi modo de ver, cuando Scheler afirma que el odio alcanza la esencia axiológica ideal peculiar de un individuo, no hace sino una concesión al hecho de que lo odiado es el ser así individual del objeto.
} 
El segundo problema que queda abierto a partir de la teoría de Scheler es el de la especificidad de la experiencia del odio vivida por el sujeto que lo padece. En efecto, el entero análisis de Scheler se dedica a explicitar qué y cómo se da el objeto odiado en el acto de odio. Pero el odio, como todo sentimiento, no implica sólo un modo de sentir el cómo del aparecer del objeto, sino un modo de sentirse a sí mismo sintiendo el objeto. Sobre este punto el análisis de Scheler calla. En tercer lugar, aunque Scheler reconoce una positividad en el odio, esto es, la capacidad de ser un acceso genuino a su objeto, no explicita las consecuencias ontológicas y morales de esa positividad, concentrándose, por el contrario, en el estudio detallado de los valores fundamentales del amor. En este sentido cabe preguntarse lo siguiente: ¿si el odio nos revela un modo de darse del objeto, hasta qué punto es un fenómeno puramente negativo? ¿No constituye también una condición de posibilidad de la emergencia del ser en su verdad? Y, si esto último es cierto, ¿en qué medida tenemos derecho a descalificarlo por completo desde el punto de vista ético?

\section{Apuntes para una fenomenología del odio}

\subsection{La experiencia de sí en el odio y sus implicancias}

Scheler ha reconocido con acierto en el odio un sentimiento intencional genuino. Como todo acto intencional el odio implica una correlación. Estimo que es posible analizar fenomenológicamente dicha correlación no sólo centrándose, como lo hace Scheler, en las características (para él axiológicas) del objeto odiado, sino teniendo en cuenta también el modo en que se da y se experimenta a sí mismo el sujeto que odia cuando mienta su objeto bajo el imperio del odio, y las consecuencias que esta auto-experiencia implica para la elucidación de la forma en que el objeto del odio es comprendido en la correlación.

Desde esta perspectiva hay que decir, siguiendo a Aurel Kolnai, que el odio es, ante todo, un sentimiento intenso que implica una "intro-misión integral (Einsetzung) de la propia persona" (Kolnai, 2007: 101), y que -a pesar de que el uso laxo del término por momentos favorece la confusión- no debe mezclarse sin más con el ocasional desagrado que me puede producir un cierto tipo de objetos y que usualmente me lleva a confesar que, por ejemplo en mi caso, odio los kiwis. Este compromiso integral de la persona, propio de la intensidad con la que ésta experimenta el odio, ocurre, como señala también Kolnai, en una doble dimensión de profundidad y de centralidad concomitantes. Propiamente hablando no hay odio si el sentimiento tiene profundidad, si conmueve todas las fibras del ser íntimo, pero no reconoce un objeto definido en el cual se centra su intención, como ocurre, por ejemplo, en el caso de los sentimientos místicos. Tampoco lo hay si lo que se da es la aversión hacia un objeto perfectamente definido y centrado, pero que no conmueve al conjunto de mí ser. Aquí podríamos retomar el ejemplo del kiwi. "La característica de profundidad ocupa sin embargo el primer plano en relación con la de centralidad" (Kolnai, 2007:101-102). Apenas 
voy a poder odiar al ratero que me atraca en la vía pública y me roba mi cartera; sin embargo bien puedo odiar con todo mi corazón a un hombre que objetivamente no me ha hecho nada, pero que corporiza un modo de entender la vida y el mundo que me es adverso. En segundo lugar y en estricta relación con la dimensiones de profundidad y centralidad, es decir, con la intensidad con que nos sentimos integralmente a nosotros mismos concernidos por la aversión hacia un determinado objeto odiado, se halla un segundo rasgo fenomenológico esencial de la experiencia del odio: su aspecto históricoactitudinal. El odio, a diferencia de, por ejemplo la ira, no es un acto -en ello era imprecisa la determinación scheleriana del fenómeno- de carácter pasajero, sino una actitud que se mantiene como un elemento esencial del sentimiento que la persona tiene de sí a lo largo del tiempo. Así los padres pueden ser presos de la ira por alguna tontería que cometa su hijo e incluso castigarlo duramente, pero no por ello lo odian. En cambio el odio hacia alguien, que no necesariamente tiene que estar acompañado por una irrupción violenta de ira, constituye constantemente un elemento esencial y determinante de la configuración que va adquiriendo la vida del sujeto que odia y, en tal sentido, "el odio es un aspecto histórico de la vida humana" (Kolnai, 2007:101-102). Se podría, incluso, ir más allá de los análisis de Kolnai y reconocer la potencialidad ontológica del odio, precisamente en cuanto constituye un elemento esencial del modo en que el existente que odia configura históricamente su propio "ser-en-el-mundo". Ahora bien, si el odio puede comprometer a la persona por entero, ser histórico y constituir un elemento determinante en la configuración que va asumiendo la vida a lo largo de su desarrollo, es porque el sujeto que odia toma "en serio" al enemigo u objeto de odio, es decir, lo experimento de alguna manera como importante, significativo, peligroso, dañino, etc. Estos diversos calificativos apuntan en el fondo a lo siguiente: en el odio me siento ofendido u agredido intencionalmente por el otro en un aspecto que considero esencial de mi propio ser y, consecuentemente, le reconozco una significatividad y un poder relevantes. De esta característica de mi auto-experiencia en el odio se derivan dos consecuencias directas. En primer lugar, que el odio es posible sólo respecto de un objeto al que se le reconoce la dignidad de la libertad y, por ende, de la responsabilidad de los actos que comete para conmigo. Sólo porque es considerado responsable, aquel que odio puede ser tomado por malvado. Nadie en su sano juicio odiaría a la lluvia por haberle ocasionado una inundación. En segundo lugar, el hecho de que el odio, a diferencia de lo que afirmaba Scheler, sólo puede estar dirigido a otro ser personal y espiritual $^{4}$, y no a una cosa u objeto natural. No hay problema en conceder que puedan darse casos extraños de odio a algo inanimado o a personas irresponsables, pero estos no son sino irradiaciones o traslaciones de un odio de base personal como, por ejemplo, cuando alguien odia a los niños inocentes de un antiguo enemigo o a las flores de las que tanto gustaba la mujer que lo traicionó. La necesaria contracara de este tomar en serio

\footnotetext{
${ }^{4}$ Aquí entiendo espíritu en el estricto sentido kierkegaardiano. Espíritu es el sí mismo, es decir, aquella relación que en la relación con lo otro se relaciona (elige) a sí mismo. El espíritu es el ser del hombre en tanto el hombre -a diferencia de las cosas que están en relación con los otros entes, pero que no se relaciona a sí mismas en esa relación- es una relación que se relaciona a sí misma. Cf. Søren Kierkegaard, La enfermedad mortal, trad. D. Gutiérrez Rivero, Madrid, Trotta, 2008: 33.
} 
al otro en el odio es que éste no se dirige a un aspecto circunstancial del objeto odiado (nadie odia auténticamente a alguien porque ese alguien, sumido ocasionalmente en un ataque de ira e "ido de sí mismo", lo ofendió), sino a su esencia, a la índole profunda de ser del otro, que es aquello que propiamente me agrede u ofende en mi propia esencia. Esta observación de Kolnai resulta decisiva (Kolnai, 2007:104). En efecto, el verdadero odio odia un modo de acaecer del ser que sólo se manifiesta y configura a través de la propia configuración del "ser-en-el-mundo" de la persona odiada. Sin embargo el odio no se dirige a la esencia del objeto odiado considerada abstractamente en sí misma, "sino bajo la más aguda acentuación de la repercusión de esta esencia sobre el sujeto que odia" (Kolnai, 2007:104). Odiamos, pues, la esencia del otro, la figura estructural fundamental que conforma su "ser-en-el mundo"; y lo hacemos en cuanto esta esencia repercute del modo más agudo posible sobre nosotros mismos, es decir, en la medida en que esta esencia representa una imposibilidad para la consumación de nuestra propio ser. Es esencial al sentimiento de odio experimentar que no podemos hacer acaecer de modo consumado nuestro "ser-en-el-mundo", no podemos concretar nuestra voluntad de ser, a causa del ser mismo del otro odiado. De allí el impulso de aniquilación de su objeto que es característico del odio y que usualmente se le reconoce. ¿Hasta donde puede llegar este impulso? Puede ir desde la exclusión o aislamiento del rival, pasando por su vilipendio público, hasta el asesinato, e incluso en los casos patológicos hasta el impedimento de los rituales religiosos del sepelio y la profanación de su tumba. Todo depende de la intensidad de la voluntad de odio. Sobre estas circunstancias concretas no puede expedirse un análisis filosófico, pero ciertamente es consubstancial a aquella intención que llamamos odio un cierto deseo de aniquilación del enemigo, que puede manifestarse de los modos más variados, pero que es siempre la contracara dialéctica de una voluntad de ser imposibilitada por el ser mismo del rival.

La principal diferencia de esta perspectiva de análisis, inspirada, por cierto, en las descripciones de Kolnai, en relación con la comprensión scheleriana del odio podría formularse en los siguientes términos: ya no se trata en el odio de una captación del rango in crescendo de los disvalores - de una cuestión axiológica-, sino de un conflicto ontológico - de un conflicto en el orden mismo del acaecer del ser. En efecto, no odio los potenciales disvalores de otro captados por un acto puro y aislado del sentimiento, sino que odio el ser mismo del otro, la configuración esencial de su "ser-en-el-mundo" que constantemente impide la consumación de mi propia esencia, de la figura estructural de mi propio "ser-en-el-mundo", en tanto y en cuanto mi "ser-en-el-mundo" es ya siempre "ser-con" el otro odiado. Por ello el odio es una actitud constante a lo largo de nuestra vida "con" ese otro y no un acto, una mera captación, que bien puede ser ocasional, de los disvalores crecientes de un individuo. De hecho tal captación podría ser neutral (o despreciativa o descalificadota), pero no estar acompañada necesariamente por odio alguno, si el ejercicio de los disvalores que caracterizan al otro no entra en conflicto con la realización o consumación de mi propio ser e intereses. Por ello también el ímpetu de aniquilación (que nunca termina de tener un sentido claro en la teoría de Scheler, ya que los disvalores como tales no pueden aniquilarse) adquiere ahora una significación definida. El odio quiere aniquilar porque odia lo que por excelencia es aniquilable: el ser 
del otro o, para decirlo más propiamente, la configuración o sentido que asume el ser a través de la existencia del otro. El testimonio más claro de este carácter ontológico y no axiológico del odio es que odiamos al otro no sólo por sus faltas, sino también por sus valores. Quien odia no quiere convertir o mejorar al otro. Ello implicaría ya un cierto amor por él. Como con razón observa Kolnai, cuando nosotros odiamos profundamente no queremos de ningún modo educar ni ennoblecer al otro. "Por el contrario, no son sus falencias sino sus valores, los que nos molestan, y no lo queremos ver mejor, sino objetivamente peor" (Kolnai, 2007:107). Es verdad que ciertos disvalores que percibimos en una persona amada nos afligen y que podemos intentar mejorarla en ese aspecto, pero, a la inversa, al sujeto que odia, como odia el ser mismo del otro, le molestan, le dañan incluso aquellas perfecciones y valores que ayudan al otro a consumar su ser.

\section{2 El aparecer del otro en el odio y sus implicancias}

En este análisis del odio como actitud ontológica nos hemos centrado principalmente hasta ahora en el lado subjetivo de aquella correlación que es el fenómeno en tanto sentimiento intencional, esto es, en el modo en que se experimenta a sí mismo el sujeto que odia. Desde esta perspectiva hemos encontrado -a través de una libre interpretación de los análisis de Kolnai- que quien odia se siente de una manera continúa e intensa ofendido o agredido intencionalmente por el otro. Ésta no es una agresión u ofensa cualquiera, sino una tal que le hace sentirse imposibilitado de consumar su propio "ser-en-el mundo"; y lo que lo agrede u ofende tampoco es una cualidad circunstancial de la persona odiada, sino un aspecto esencial de su ser, un trazo determinante de la configuración que asume su "ser-en-el-mundo-conmigo". Razón por la cual a la experiencia de sí del odio le es inherente también un ímpetu aniquilador. Pero un análisis integral requiere que ahora fijemos la mirada en la otra perspectiva posible, en el correlato objetivo, y nos preguntemos cuál es el fundamento del odio, esto es, aquellas características que determinan esencialmente el modo en que se nos da el objeto al que el odio se dirige. En otras palabras, que nos preguntemos por el ser mismo de lo odiable. En este sentido también los análisis de Kolnai son de gran ayuda. Ante todo el autor reconoce en el odio una doble motivación (Kolnai, 2007:109). Que en principio esta presente en todos los casos del fenómeno. Por un lado el odio capta la constitución misma (Beschaffenheit), el modo de ser de su objeto, y, por otro, capta el rol dinámico del objeto, es decir, el modo en que el ejercicio de su constitución repercute en contra de mi propio inter-esse, esto es, de mi propio interés por ser. Ambos aspectos del objeto se dan siempre conjuntamente, aunque, según el caso, pueda tener más peso uno u otro de ellos. El ser mero agente de un daño o agresión que yo pudiese padecer no es suficiente motivo para considerar al otro odiable, si el daño no está vinculado necesariamente con la constitución misma del agente. Así no se odia, aunque sí se puede temer en grado sumo, al loco que es éticamente irresponsable y que puede llegar incluso a cometer atrocidades; pero sí a aquel otro que descubre su esencial rencor a través de una traición, aunque tal vez ella provoque un daño objetivamente menor que la acción del desquiciado. Tampoco se odia al rival leal y caballeresco que compite conmigo por 
un cierto logro, y sí en cambio a aquel que lo hace maliciosamente, por ser él mismo una persona pérfida. Inversamente no odio, aunque sí pueda despreciar en grado sumo, a aquel individuo a todas luces mentiroso, hipócrita y traidor, pero que a mí propiamente no me ha hecho ni puede hacerme nada, ni tampoco constituye obstáculo alguno para la realización de mi vida; y sí en cambio a aquel otro, que tal vez no es tan despreciable como el primero, pero cuya maldad me afecta personalmente. "No se va por el ancho mundo tratando de detectar malvados a los que se podría odiar a gusto y con razón; se odia sólo el mal que de algún modo llega hasta mí, penetra en el círculo vital del sujeto y donde le es posible origina también daños" (Kolnai, 2007:110). En síntesis, el objeto del odio aparece bajo un doble aspecto y, correlativamente, el odio reconoce una doble motivación. Por un lado odio el modo mismo en que se me da la constitución esencial del objeto, pero, por otro, el hecho de que el ejercicio de dicha constitución me afecta o daña personalmente.

De cada uno de estos dos aspectos propios de la duplicidad característica del modo de aparecérseme el objeto en el fenómeno del odio, se derivan sendos rasgos esenciales del mismo. En primer lugar, del hecho de que odio la constitución esencial del otro, es decir, los rasgos estructurales que conforman su personalidad, resulta el carácter de acontecimiento del fenómeno. En efecto, el odio, como el amor, no es algo que yo decida, sino que me ocurre, que padezco independientemente de mi voluntad y que puede surgir en mí incluso en contra de ella, precisamente porque no es cuestión de mi voluntad ni de mi poder determinar la constitución esencial de aquel otro que me sale al encuentro y cuyo ser así genera en mí la llama del odio. En este sentido el odio es por esencia anti-patía: el padecer negativamente el dárseme del otro. Su salirme al encuentro es padecido (pathos) como contrario (anti) a mi propio ser. Ahora bien, si el odio es un pathos -el pathos antipatético- él, como todo pathos, representa también un límite impuesto a mi poder sobre el ser de lo que se da. El propio impulso de aniquilación es la confesión de esta imposibilidad del sujeto de determinar o reducir a una figura aceptable para él esa constitución esencial del otro que tanto odia. En este sentido el odio, antes que un reconocimiento de mi objetividad ante el otro, es un reconocimiento de la alteridad de ese otro. ${ }^{5}$ En segundo lugar, del hecho de que odio el daño personal que me infringe el otro resulta un nuevo rasgo determinante del odio que podríamos llamar "vínculo existencial". No odio a ningún extraño con el que no mantengo relaciones estrechas, sino a aquel que es significativo para mí existencia, que, de algún modo

\footnotetext{
5 En este punto es donde resulta altamente cuestionable la idea de Sartre de que el afán de aniquilación propio del sujeto que odia surge de su intento por "recobrar una libertad sin límites de hecho, es decir, desembarazarse de su inaceptable ser-objeto-para-el-otro y abolir su dimensión de alienación." (Sartre, 1966: 509). A mi modo de ver, si lo que quiero es eliminar la imagen objetiva que otro se hace de mí, entonces tendría que querer eliminar a todos los otros, odiar a cada uno de ellos, porque ciertamente cada uno se hace una imagen objetiva del otro de acuerdo con el tipo de relación existente entre ellos. Pero, más allá de que fácticamente éste no es el caso, el hecho de que bien puedo odiar la imagen que el otro se haga de mí no resuelve la cuestión de fondo, porque lo que odio es que el sea de tal modo que pueda tener esa imagen de mí y que yo no pueda evitarlo. Por lo tanto ese impulso de aniquilación va en última instancia dirigido al ser del otro, a lo que hemos llamado su constitución, y es una confesión de mi imposibilidad para poder reducir ese ser a mis deseos o intereses.
} 
forma parte de mi "ser-en-el-mundo" que es ya siempre un "ser-en-el-mundo-con-él". De allí que sea más intenso el odio cuanto más estrecha haya sido la relación, porque mayor y más íntima resulta, entonces, la afrenta padecida. El ejemplo típico de ello es el odio al antiguo conyugue que suele acompañar a numerosos procesos de divorcio. La interrelación dinámica, el vínculo existencial del que siente odio por su objeto, es una condición esencial del fenómeno. Con razón observa Kolnai que, aunque aparentemente ciertas formas de odio, parecieran, a primera vista, estar libres de esta condición, se revelan a un vistazo más agudo sometidos a ella. Así, por ejemplo, el odio a otras religiones o culturas pareciera estar ligado exclusivamente a la constitución esencial de esa otra religión o mundo cultural y ser independiente del daño que propiamente ella haya hecho a mi propio mundo religioso o cultural; pareciera tratarse, pues, de un odio dirigido exclusivamente al modo de ser del otro. El contacto, la cercanía, la historia de las relaciones y los vínculos entre esas dos culturas y las afrentas o daños que mutuamente se hayan causado constituyen, sin embargo, un elemento esencial del odio. Así, por ejemplo, el odio entre cristianismo y judaísmo o entre judaísmo e islamismo es moneda usual, pero resultaría muy extraño un odio encarnizado del cristiano por el paganismo malayo o del judío por las creencias de los wichís.

En síntesis, el odio, como fenómeno ontológico, implica dos componentes concomitantes resultantes de los dos modos co-implicados en que aparece su objeto: como agente de un daño y como constitución esencial. Por un lado hallamos, pues, su núcleo desencadenante representado por un cierto suceso o estado de cosas que vincula a los términos de la correlación (por ejemplo, la competencia de dos caballeros por una misma dama) y que obra como la matriz en la que crece la ofensa, el agravio o el daño personal de uno a otro. Pero el suceso o estado de cosas en el que surge el conflicto precisamente "desencadena" o "desata" el odio, no lo crea. Entra aquí en juego, por otro lado, el segundo componente, aquello que es desatado para que el odio se consume, a saber: una oposición fundamental de modos de ser o, como también podría decirse, una "anti-patía personal" resultante de distintas cualidades, distintos modos de comprender la vida, distintas convicciones, en una palabra, distintas maneras de asumir el sentido del ser de lo que es en la propia existencia, que ahora se vuelven patentes y entran en conflicto en función de un determinado estado de cosas o mundo en común. Ninguno de los dos aspectos puede faltar para que el odio exista.

\section{El significado del odio}

Hasta aquí hemos analizado los rasgos fenomenológicos esenciales del odio desde la perspectiva de la experiencia de sí del sujeto que odia y del modo en que se le da a él el objeto de odio. Ahora el momento fenomenológico cede su primacía al hermenéutico, esto es, a la explicitación del significado del odio. Dado que hemos considerado el odio como una oposición ontológica, su significado ha de buscarse en primer lugar en esa dimensión.

Desde la perspectiva ontológica podemos reconocer obviamente una significación negativa, pero también una positiva del odio. Por "negativo" entendemos 
aquí un proceso de empobrecimiento ontológico, es decir, de ocultamiento o supresión de las diferentes configuraciones de sentido que el existente proyecta en el todo del ente: una merma, un desfallecimiento en la diversidad del ser. Por "positivo" un proceso de enriquecimiento por el cual el ser o sentido viene a la luz y se configura con rostros cada vez nuevos y diversos: un alumbramiento de nuevos modos del ser. Si asumimos que lo que define al hombre es comprenderse comprendiendo el ser de todo aquello con lo que está en relación (mundo), y si asumimos también que dicha comprensión acontece esencialmente a partir de la elección de un posibilidad de ser que es, al mismo tiempo, una posibilidad de relacionarme con el mundo, entonces tendremos que distinguir una doble significación negativa y una doble significación positiva del odio, según pongamos la mirada en uno u otro de los términos de la correlación: el sujeto del odio o su objeto. La significación negativa desde la perspectiva del objeto odiado es obvia e inherente al impulso de aniquilación que vive en el odio. El odio quiere anonadar al otro, quiere acabar con su ser; y no sólo con su ser físico, ni, como creía Sartre (1966: 509-510), con la imagen objetiva que él tiene de mí, sino con su constitución esencial, con su modo esencial de ser, esto es, con la figura que el ser asume a través de la existencia del otro. No odiamos a Juan o a José, sino que, concomitantemente, odiamos el modo en que Juan y José comprenden la vida y son y obran en el mundo. Como impulso de aniquilación de un modo de ser, que es un modo del ser, el odio constituye un proceso negativo desde el punto de vista ontológico. Centremos ahora la mirada no en el objeto odiado, sino en el sujeto odiante. Ortega con mucha razón ha escrito que el amor es "un fenómeno de la atención" (1984: 100); más específicamente "un estado anómalo de ella" (1984: 102); un proceso de concentración atencional "que lleva a una progresiva eliminación de las cosas que antes nos ocupaban" (1984: 104). Esta paralización de la atención, que queda "presa de un solo ser" (1984: 104), lleva a un paulatino empobrecimiento de nuestra actividad mental. La "conciencia se angosta" (1984: 104), escribe Ortega. Pues bien, estimo que otro tanto podría afirmarse del odio; y con tanta más razón cuanto más intenso sea el sentimiento. El mundo del sujeto que odia -al concentrarse en el objeto odiado y en el afán de aniquilarlo- se empobrece, se desrealiza. Las múltiples posibilidades de ser del desventurado que ha sido atrapado por el odio se evaporan y sus fuerzas son consumidas por una pasión obsesiva. Desde este punto de vista, es decir, desde el del correlato subjetivo del odio, podría, pues, también afirmarse que el odio representa un empobrecimiento en el orden del ser mismo del sujeto que odia, ahora restringido a su relación obsesiva y concentrada con su objeto. Pero el odio es un fenómeno multifacético, dinámico y, sobre todo, ambiguo. Escapa a definiciones rígidas que quieran agotar desde una sola perspectiva el modo en que el fenómeno mismo acaece, se temporaliza y significa. En efecto, visto desde otra perspectiva, dialécticamente complementaria con la anterior, el odio puede significar en clave ontológica también de modo positivo. ¿En qué sentido? Comencemos aquí también por el correlato objetivo. Así como el amor descubre perfecciones en el ser del amado a las que son ciegas otras facultades y sentimientos, así también el odio es la intencionalidad genuina y específica que permite descubrir con una intensidad y finura aspectos del ser del otro -en este caso aquellos aspectos y cualidades de su ser que entran en conflicto con el mío propio- que 
de otro modo y sin su poder de concentración atencional no verían la luz. ${ }^{6}$ El odio tiene, pues, una función positiva o, mejor sería decir, reveladora o des-ocultante del ser: por él accedo a aquellos trazos o rasgos esenciales del "ser-en-el-mundo" del otro odiado que permanecen ocultos a aquellos incapaces de odiar. Además, cuando la relación de odio es mutua, ella constituye un nutriente que alimenta el desarrollo de los rasgos odiados. Así como el amor, a través y en virtud de mi "ser-con" el otro, tiene la capacidad de corealizar las perfecciones que atisbo en potencia o latentes en él, el odio tiene el mismo poder de realizar el ser-odiado de quien odio. Cuando el odio es mutuo, el mismo odio fortalece e intensifica los modos de ser respectivamente odiados. Así el odio a un enemigo religioso y a su modo de comprender la relación con lo divino, hace que él acentúe los rasgos de su religión para mí tan siniestros. En síntesis, el odio es positivo ontológicamente en cuanto, por un lado, advierte aspectos positivos, esto es, efectivos del ser del otro que escapan a otras facultades y sólo para él devienen patentes y, por otro, es un factor que ciertamente quiere aniquilar al otro, pero en tanto y en cuanto no

\footnotetext{
${ }_{6}$ Paola Ludovica Coriando en el marco de una interpretación heideggeriana de Scheler ha negado recientemente este carácter positivo del odio. Para la estudiosa el odio, a diferencia del amor, no entra en contacto originario con su objeto, sino que permanece preso de una re-producción subjetiva (y negativa) de la realidad. Escribe Coriando: "No hay nada comparable en el odio a la plenitud significativa que despunta e irrumpe en el amor, el cual anímicamente pone en libertad la relación al mundo y al otro. El odio, por cierto, nos deja ver el otro y el mundo de otra manera, sin embargo lo hace de un modo tal que en él nosotros no somos deslimitados, sino que nos dejamos limitar por y caer prisioneros del impulso aniquilador propio del ciego imputar y querer saldar una cuenta. Por eso no puede el odio, comprendido esencialmente, alcanzar el estatus de un temple fundamental" (Ludovico Coriando, 2002: 185). Desde una perspectiva puramente fáctico-pragmática se podría decir que de hecho el odio es tan fundamental como el amor, puesto que a él le debemos quizá tantos (sino más) acontecimientos decisivos en la historia de la humanidad. Piénsese en las guerras de religión o en los genocidios. Pero piénsese también en procesos revolucionarios o de liberación surgidos motivacionalmente del odio a una tiranía u opresión. Sin embargo, más allá de ello hay que decir que Coriando, al referirse al impulso ciego de querer ajustar cuentas o imputar cargos, no advierte el problema central, a saber, que el odio puede descubrir aspectos esenciales de la realidad odiada, ocultos a otra intencionalidad, y que son precisamente esos aspectos los que originan y eventualmente pueden justificar el subsiguiente impulso ciego; pues éste no se genera por que sí, por un mero capricho o "reproducción subjetiva" (subjektive Abbildung) del sujeto que odia, sino que tiene su razón de ser en la correlación entre éste y la índole propia del objeto odiado. Ciertamente y con razón se puede decir que el odio en sus formas degradadas o sentimentales -en el estricto sentido que Scheler usa esta palabra- puede proyectar en el otro rasgos negativos que en realidad no se encuentran en él, y que la consecuente re-producción que de él hacemos nos limita y mantiene prisioneros para tener una relación originaria con la esencia de ese otro y del mundo. Sin embargo ello es propio de las formas degradadas o sentimentales del odio o también un epifenómeno del mismo, pero originariamente el odio no surge de la proyección, sino de la correlación con el ser del objeto. No es la reproducción la que general el odio, sino el odio el que genera la reproducción y el impulso ciego. Y ese odio tiene su origen en la manifestación de un aspecto del objeto, tal como lo tiene el amor, entendido genuinamente. Además, contra la incomparabilidad afirmada por la autora entre amor y odio es necesario reconocer que también resulta absolutamente característico del amor en sus formas degradadas proyectar idealizaciones del objeto amado que obran como un impulso igualmente ciego, pero esta vez en pro y no en contra del otro. Este impulso positivo, como el negativo del odio, nos limita igualmente a relacionarnos de modo originario con la verdadera esencia del objeto amado. En síntesis, no se ve por qué el odio no podría, como el amor, descubrir aspectos del ser de lo odiado, ni cómo (si se le reconoce a la afectividad como lo hace Coriando el carácter de una intencionalidad que accede genuinamente a su objeto) se puede negar desde fuera del odio la capacidad de revelar aquello que sólo se revela en el odio.
} 
lo logre, lo que hace es nutrir el desarrollo y potenciar los rasgos adversos del ser de aquel que odia. Ahora bien el odio no es sólo positivo desde la perspectiva de su descubrir o co-crear aspectos del ser del objeto odiado, sino también desde la perspectiva del sujeto que odia. En este sentido hay que recordar ante todo lo afirmado más arriba, a saber, que el odio presupone un compromiso personal con el ser de parte de quien lo ejerce, es decir, presupone que éste haya empuñado conscientemente su ser más propio, que se haya elegido a sí mismo y que, por tanto, haya elegido una forma o figura ideal del mundo en el que quiere ser. A quien le da todo lo mismo, quien, como diría Heidegger, es como "uno" cualquiera y se ha entregado en cuerpo y alma a la existencia impersonal, ése no tiene la posibilidad de odiar. Quien no se elige a sí mismo en su relación con los entes ni, por tanto, tampoco tiene una relación o interés auténtico por el ser de los otros y de las cosas, a ése, por supuesto, el odio le es ajeno. Este hombre de término medio, que pasa por la vida como una sombra gris que se desvanece sin dejar rastro, no tiene ni la fuerza ni la enjundia para odiar. Él no aborrece ninguna figura del mundo que entre en conflicto con la suya, porque no tiene ninguna. No hay modo de ser que se le enfrente, porque no le inter-esa el ser, ni el suyo, ni el del mundo, ni el del otro. Es, como Kierkegaard lúcidamente lo ha catalogado, un falto de espíritu. Está libre del odio, pero no porque esté por encima de él, sino porque está por debajo, pues el odio es una fuerza y una pasión del espíritu. Sólo aquel al que "le va" el ser y se compromete con él, aquel que no cesa en su empeño de alumbrar con una nueva luz los contornos de lo real, puede odiar toda oscuridad que se ciña sobre esa realidad. Sólo quien tiene ideales, quien se interesa por el ser, quien se haya comprometido con una determinada figura del mundo, en una palabra, quien es un sí mismo espiritual y asume su condición de tal, puede tener enemigos y puede odiar. En este sentido la positividad no es propiamente del odio, sino de la posibilidad de odiar. Kierkegaard afirmaba que sólo quien puede desesperar, puede alcanzar la salvación. Algo similar podría decirse del odio. Sólo quien puede odiar se relaciona verdaderamente con el ser, con el suyo y con el del mundo. El odio es un testimonio dialéctico ineludible de una seria pasión por el ser; y esta seriedad, a su vez, es la evidencia de haber asumido la propia condición espiritual: de haberse elegido a sí mismo y haber elegido, por lo tanto, lo otro en relación con lo cual se realiza el sí mismo. De allí que el afán de aniquilación propio del odio, con toda la negatividad que comporta, no sea sino el reverso dialéctico de un innegable afán de realización. En este específico sentido testimonial (y no sólo por la capacidad de mostrarnos otros aspectos del objeto) el odio es ontológicamente positivo.

Puede, por cierto, llegar a aceptarse una positividad ontológica del fenómeno, pero afirmar una positividad ética ¿no es un desvarío? Sobre la negatividad ética del odio se han escrito innúmeras páginas en la filosofía, la teología y las obras de espiritualidad. No me parece necesario aquí engrosarlas. Todas ellas apuntan a la misma cuestión: la concentración e intensidad con que el afán de aniquilación domina al sujeto del odio, cuando se sobrepone a todo juicio racional, puede llevar y usualmente lleva a la violación de toda norma ética y a cometer las infamias más atroces. En el fondo entregarse al odio es entregarse por completo al egoísmo, pues odio aquello que va en contra de mi interés personal y me impide consumar mi propio ser. Aunque no me interesa insistir 
en este aspecto, quisiera llamar la atención sobre aquella forma extrema de odio en la que el fenómeno alcanza un rango que trasciende el plano estrictamente ético y alcanza lo religioso-demoníaco. Ello ocurre cuando el odio, por su misma intensidad, deja de ser un sentimiento y se convierte en una pasión. Ya no es tan sólo un modo del sujeto de dirigirse a su objeto, sino que la sensibilidad del sujeto ante su objeto se exacerba hasta un punto tal que ese objeto de odio se convierte para él en todo su mundo y en la meca de todas las maldades imaginables. Se produce así un proceso de demonización del otro, que no reconoce límite moral ninguno y que no se contenta ni siquiera con la muerte física del otro, sino que aspira, como bien señala Scheler, incluso a su "perdición eterna" (Scheler, 2004: 220). Lo propio de esta forma extrema del odio es, por un lado, la imposibilidad de distinguir entre las maldades reales y todas aquellas otras que el obsesionado proyecta en su objeto de odio, y, por otro, la completa identificación entre la persona odiada y la maldad en sí misma. Pues bien, todo lo contrario ocurre cuando el odio cobra, desde el punto de vista ético, un significado positivo. Dos son, entonces, las precondiciones para que ello ocurra. Por un lado, es menester que el odio sea justificado, es decir, que aquella constitución esencial del otro que odio no sólo sea odiada porque se opone a mi propio ser, sino por ser malvada, injusta, inmoral o indigna en sí misma. Es necesario, pues, que al odio pertenezca aquello que Bollnow le reconocía a las formas legítimas de la ira, a saber: "la conciencia de la justificación y la consonancia con el orden ético objetivo" (Bollnow, 1947: 109). Por otro lado, es menester que el sujeto que odia distinga los dos aspectos propios del odio antes señalados: el otro que me infringe un daño y la constitución esencial o modo de ser que se manifiesta o expresa a través de él. Cuando el odio se concentra en esa constitución esencial, es decir, en aquel modo de ser que se expresa paradigmáticamente en el otro (y no tan sólo en la persona del otro) y cuando, además, ese modo de ser es objetivamente malvado, el odio se sublima a sí mismo y deviene justa indignación. Es cierto que la sublimación nunca es completa y que el odio, por su propia esencia, va más allá de la mera rivalidad objetiva. Sin embargo, siempre existe la posibilidad de redirigir y circunscribir la confrontación estrictamente interpersonal a aquella zona en la que lo que está en juego no son tanto las personas por sí mismas, sino el sentido y la dignidad de la existencia humana, ofendidos por quien con sobrado motivo se ha ganado mi odio. Cuando ello ocurre, el odio está en camino de convertirse en indignación y en condiciones de desplegar toda su positividad ética latente. Es entonces cuando en él se reconoce un factor motivacional crucial de la eterna lucha contra la injusticia, la tiranía, la maldad, la opresión o la estupidez. Es entonces también cuando este odio "purificado" contribuye a reafirmar la voluntad personal de hacer ser a través de la propia existencia todo aquello que, con buena conciencia, se considera digno de ser. ${ }^{7}$

Kierkegaard decía que sólo el que ha pasado por la desesperación puede conquistarse auténticamente a sí mismo. Pero aclaraba también que la desesperación

\footnotetext{
7 En este sentido y como bien señala Kolnai "se eleva la pregunta acerca de si la combatividad, el espíritu reformador, la crítica a los imperios establecidos serían posibles sin odio, o si incluso la afirmación de la propia identidad personal, que es inseparable de la confrontación en torno a cuestiones objetivas de valor, podría avanzar sin ninguna concesión al odio." (Kolnai, 2007: 138).
} 
es "la enfermedad, no el remedio". Sus frutos sólo los recoge aquel que se ha curado. Estimo que algo similar podría decirse del odio. Sus frutos éticos positivos no radican en él, sino en su sublimación como indignación. Pero una indignación que contenga todo el fervor, la sinceridad y la fuerza del odio, debe haber crecido de éste. Aquí radica la luminosidad de un fenómeno que por lo común merodea entre las sombras. Es cierto que nunca brillará con el fulgor espléndido con que su hermano eros suele cegarnos, pero me parece injusto no reconocerle ni un solo destello de luz propia.

\section{Referencias bibliográficas}

Bollnow, O. F. 1947. Einfache Sittlichkeit, Göttingen, Vandenhoeck.

Kierkegaard, S. 2008. La enfermedad mortal, trad. D. Gutiérrez Rivero, Madrid, Trotta, 2008.

Kolnai, A. 1931. Philosophisches Jahrbuch der Görres-Gesellschaft, 44 Band, 2. Heft.

Kolnai, A. 2007. Eckel, Hochmut, Haß. Zur Phänomenologie feindlicher Gefühle, Frankfurt a. M., Suhrkamp.

Ludovico Coriando, P. 2002. Affektenlehre und Phänomenologie der Stimmungen. Wege eine Ontologie und Ethik des Emotionalen, Frankfurt a. M., Vittorio Klostermann.

Ortega y Gasset, J. 1984. Estudios sobre el amor, Madrid, Espasa Calpe.

Sartre, J. P. 1966. El ser y la nada. Ensayo de ontología fenomenológica, trad. J. Valmar, Buenos Aires, Losada.

Scheler, M. 2004. Esencia y formas de la simpatía, trad. J. Gaos, Bs. As., Losada.

Strasser, S. 1956. Das Gemüt. Grundgedanken zu einer phänomenologischen Philosophie und Theorie des menschlichen Gefühlslebens, Freiburg, Herder. 
